\title{
Quantitative Assessment of Cervical Vertebral Maturation Using Cone Beam Computed Tomography in Korean Girls
}

\author{
Bo-Ram Byun, ${ }^{1,2}$ Yong-Il Kim, ${ }^{1,2,3}$ Tetsutaro Yamaguchi, ${ }^{4}$ \\ Koutaro Maki, ${ }^{4}$ and Woo-Sung Son ${ }^{1,2}$ \\ ${ }^{1}$ Department of Orthodontics, Dental Research Institute, Pusan National University Dental Hospital, Geumoro 20, \\ Yangsan 626787, Republic of Korea \\ ${ }^{2}$ Department of Orthodontics, School of Dentistry, Pusan National University, Yangsan 626870, Republic of Korea \\ ${ }^{3}$ Department of Orthodontics, Biomedical Research Institute, Pusan National University Hospital, Gudeokro 179, \\ Busan 602739, Republic of Korea \\ ${ }^{4}$ Department of Orthodontics, School of Dentistry, Showa University, Tokyo 1428555, Japan
}

Correspondence should be addressed to Yong-Il Kim; kimyongil@pusan.ac.kr and Woo-Sung Son; wsson@pusan.ac.kr

Received 13 January 2015; Accepted 13 March 2015

Academic Editor: Chuangyin Dang

Copyright (C) 2015 Bo-Ram Byun et al. This is an open access article distributed under the Creative Commons Attribution License, which permits unrestricted use, distribution, and reproduction in any medium, provided the original work is properly cited.

\begin{abstract}
This study was aimed to examine the correlation between skeletal maturation status and parameters from the odontoid process/body of the second vertebra and the bodies of third and fourth cervical vertebrae and simultaneously build multiple regression models to be able to estimate skeletal maturation status in Korean girls. Hand-wrist radiographs and cone beam computed tomography (CBCT) images were obtained from 74 Korean girls (6-18 years of age). CBCT-generated cervical vertebral maturation (CVM) was used to demarcate the odontoid process and the body of the second cervical vertebra, based on the dentocentral synchondrosis. Correlation coefficient analysis and multiple linear regression analysis were used for each parameter of the cervical vertebrae $(P<0.05)$. Forty-seven of 64 parameters from CBCT-generated CVM (independent variables) exhibited statistically significant correlations $(P<0.05)$. The multiple regression model with the greatest $R^{2}$ had six parameters $(\mathrm{PH} 2 / \mathrm{W} 2$, UW2/W2, $(\mathrm{OH}+\mathrm{AH} 2) / \mathrm{LW} 2, \mathrm{UW} 3 / \mathrm{LW} 3, \mathrm{D} 3$, and $\mathrm{H} 4 / \mathrm{W} 4)$ as independent variables with a variance inflation factor $(\mathrm{VIF})$ of $<2$. CBCTgenerated CVM was able to include parameters from the second cervical vertebral body and odontoid process, respectively, for the multiple regression models. This suggests that quantitative analysis might be used to estimate skeletal maturation status.
\end{abstract}

\section{Introduction}

Knowledge of bone age is necessary in order to determine treatment timing in orthodontic and orthognathic surgery patients. Many researchers have introduced a variety of biological indicators [1-4] including chronologic age, dental development, sexual maturation, voice change, and body height [5-9]. Unfortunately, chronologic age alone is not a reliable indicator for the evaluation of skeletal maturation.

Among biological skeletal maturation indices, skeletal maturation indicators that use hand-wrist radiographs are popular and reliable approaches in orthodontia clinics. However, this method requires a hand-wrist radiographic film. There has been increased interest in the use of cervical vertebral maturation $(\mathrm{CVM})$ as a replacement for the hand-wrist assessment [10-12]. Franchi et al. [11] used lateral cephalometric analysis to confirm the validity of six CVM stages as biological indicators of both somatic and mandibular skeletal maturity. Baccetti et al. [12] introduced an improved version of the CVM method for the assessment of mandibular growth. The CVM method has proven to be effective in assessing adolescent growth peaks regarding both body height and mandibular size [10-12]. However, Gabriel et al. [13] have raised issues regarding the poor interand intraobserver reliability of CVM, which are below $50 \%$ and $62 \%$, respectively. They insisted that there is inherent bias in staging and that it would be necessary to use fewer vertebral bodies, employ more sensitive parameters, and avoid estimating stage based on a comparative assessment of changes between stages, in order to make the CVM analysis 
clearer, easier, and more applicable to the majority of patients. To achieve these conditions, Chen et al. [14] suggested a quantitative CVM (QCVM) method that used parameters from the second, third, and fourth cervical vertebrae.

Among the cervical vertebrae subjected to CVM analysis, the first (atlas) and second (axis) cervical vertebrae are atypically shaped. In particular, the second cervical vertebra contains the odontoid process, which projects upward from the body. To test the more quantitative aspects of the CVM method, Chatzigianni and Halazonetis [15] applied statistical shape analysis for the evaluation of cervical vertebral shape. In their study, morphological variations of the axis retained the same ratio of height to width as that of other vertebrae. Çokluk et al. [16] used magnetic resonance imaging (MRI) to examine the region including the occiput and the first, second, and third cervical vertebrae. They reported that the average ratio of the odontoid process to the body of the second cervical vertebra was 2 in pediatric cases and 1.8 in adult cases. In the MRI study, the remnant of dentocentral synchondrosis was used as the border between the second cervical vertebral body and its odontoid process. Çokluk et al. [16] defined the borders of the body and odontoid process of the second cervical vertebra. However, a few studies still consider the second cervical vertebral body and odontoid process to be parameters for the assessment of skeletal maturation because a lateral cephalogram is unable to demarcate the second cervical vertebral body and odontoid process separately.

Cone beam computed tomography (CBCT) could be a useful tool for the three-dimensional approach to the second cervical vertebral structure. Like MRI, CBCT is able to show the remnant of dentocentral synchondrosis in the second cervical vertebra. The images obtained from CBCT could provide another approach to the CVM method by defining the second vertebral body and odontoid process, followed by the remnant of dentocentral synchondrosis. Joshi et al. [17] have already used CBCT to assess skeletal maturation and prove the reliability of CBCT when employed with CVM. In addition, CBCT is available at a lower cost and yields highquality data at relatively low radiation dosages; therefore, it has become used more commonly in dental practice [18].

This study aims to examine the correlation between skeletal maturation stage and parameters from CBCT-generated CVM (the odontoid process and the body of the second cervical vertebra and the bodies of the third and fourth cervical vertebrae), while simultaneously building multiple regression models that are able to estimate skeletal maturation status in Korean girls.

\section{Material and Methods}

2.1. Study Population. The study population included 76 patients ( 76 girls between 6 and 18 years of age) enrolled from July 2007 to December 2014. We examined the upper cervical spine of each patient using CBCT imaging (Pax-Zenith3D, Vatech, Seoul, Korea). Hand-wrist radiographs (PM2002CC, Planmeca, Helsinki, Finland) were used to determine skeletal maturation $[19,20]$. Individuals with cleft lip and/or palate,
TABLE 1: Descriptive statistics of study participants.

\begin{tabular}{lcc}
\hline Sample size $(n=76)$ & $\begin{array}{c}\text { Chronologic age } \\
\text { (years) }\end{array}$ & $\begin{array}{c}\text { Sempé maturation } \\
\text { level (SML, \%) }\end{array}$ \\
\hline Mean age & 14.6 & 83.1 \\
Maximum & 18.0 & 94.8 \\
$75 \%$ quartile & 16.6 & 90.9 \\
Median & 15.3 & 87.9 \\
25\% quartile & 13.6 & 82.7 \\
Minimum & 6 & 13.6 \\
\hline
\end{tabular}

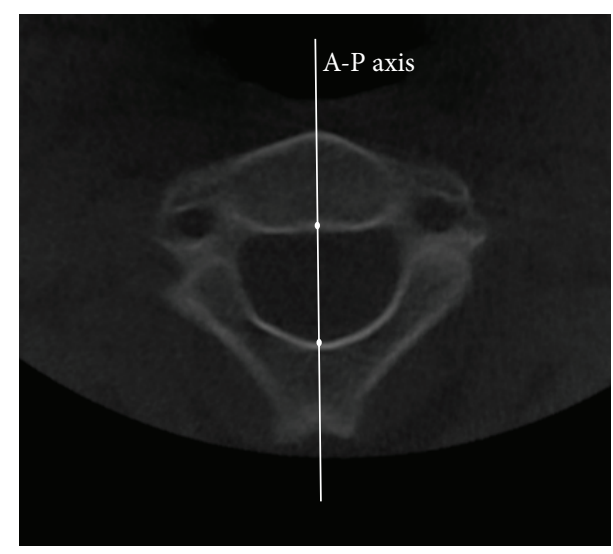

Figure 1: Anteroposterior (A-P) axis.

trauma, or syndromes were excluded from the study (Table 1). The Institutional Review Board of Pusan National University Dental Hospital reviewed and approved this study (PNUDH20104-011).

2.2. Skeletal Assessments. As a measure of participants' skeletal status, two investigators assessed the hand-wrist radiographs. The assessments were based on the Sempé maturation level (SML) and Fishman's skeletal maturation index (SMI). CBCT scans (field of view $(\mathrm{FOV}), 20 \times 19 \mathrm{~cm}$; tube voltage, $90 \mathrm{kVp}$; tube current, $4.0 \mathrm{~mA}$; and scan time, $24 \mathrm{~s}$ ) were obtained in an upright position with maximum intercuspation. Each patient's Frankfurt-horizontal $(\mathrm{FH})$ plane was set parallel to the floor. The CBCT data were reconstructed using 3D imaging software (OnDemand3D, Cybermed Co., Seoul, Korea). To obtain images of the cervical vertebrae, 3D imaging software was used under the same condition (window width at 4000, window level at 1000).

2.3. Data Acquisition. To acquire each image, first, the deepest posterior point of the second cervical vertebral foramen and the midpoint of the second cervical vertebral body were used to generate the anterior-posterior axis in the axial view (Figure 1). After the anterior-posterior axis had been set, we adjusted the vertical axis to pass through the midpoint of the odontoid process in the coronal view. The lateral image of the cervical vertebra was obtained from the plane formed by the vertical axis and the anterior-posterior axis (Figure 2). 


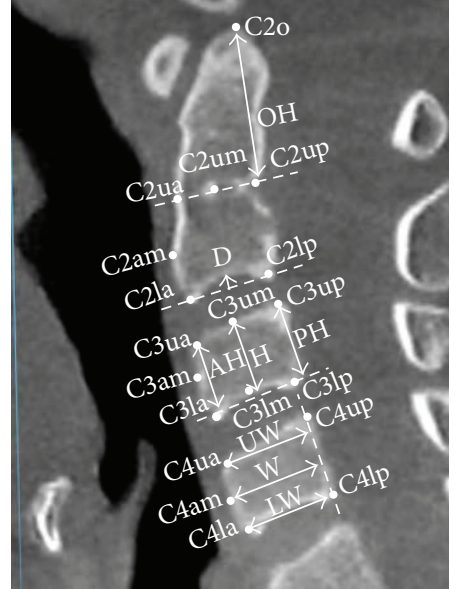

Figure 2: Parameters (distances) used in the analysis: $\mathrm{OH}$, vertical distance of $\mathrm{C} 2 \mathrm{o}$ to the line of $\mathrm{C} 2 \mathrm{ua}$ and $\mathrm{C} 2 \mathrm{up}$; $\mathrm{AH} 2-4$, vertical distance of C2-4ua to the line of C2-4lp and C2-4la; $\mathrm{H} 2-4$, vertical distance of C2-4um to the line of C2-4lp and C2-4la; $\mathrm{PH} 2-4$, vertical distance of C2-4up to the line of C2-4lp and C2-4la; UW24 , vertical distance of $\mathrm{C} 2-4 \mathrm{ua}$ to the line of C2-4up and C2-4lp; W2-4, vertical distance of C2-4am to the line of C2-4up and C24lp; LW2-4, vertical distance of C2-4la to the line of C2-4up and C2-4lp; D2-4, vertical distance of C2lm to the line of C2la and C2lp.

In this study, we adopted and modified landmarks and measurements from those described in the QCVM study by Chen et al. [14]; these parameters are defined in Figure 1 and Table 2. The border of the body of the second cervical vertebra (C2) was defined by the remnant of the dentocentral synchondrosis as visualized in the lateral image of the second cervical vertebra. For every study participant, each parameter was measured and calculated using 3D imaging software.

2.4. Statistical Analysis. The data were analyzed using statistical software (SPSS version 21.0 for Windows, Chicago, Il, USA). The statistical analyses included correlation coefficient analysis and multiple regression analysis with stepwise elimination. Multiple linear regression analysis was used to determine the SML for Korean girls as the dependent variable and parameters from CBCT-generated CVM as the independent variables. The intraexaminer and interexaminer reliability of the linear measurements were each checked by remeasurement of 20 randomly selected lateral images 2 weeks later; the intraclass correlation coefficients were very high (means of 0.993 and 0.990 , resp.). The intraobserver and interobserver errors for the SML and SMI were evaluated using Cohen's kappa index. The intraobserver and interobserver reliability for Cohen's kappa index each demonstrated substantial agreement (means of 0.805 and 0.779 , resp.).

\section{Results}

To prove that the SMI and SML are comparable, we used Pearson's correlation coefficient analysis to determine the correlation between the SMI and SML, which we then defined as the skeletal maturation status index. This value exhibited
TABLE 2: Landmarks and measurements.

\begin{tabular}{ll}
\hline Parameter & Description \\
Landmarks & $\begin{array}{l}\text { The most superior point of the odontoid } \\
\text { process } \\
\text { The most superior points of the lower } \\
\text { border of the bodies of C2-4 } \\
\text { C2-4lm }\end{array}$ \\
The most anterior (a) and posterior (p) \\
points on the lower border of the bodies \\
of C2-4 \\
The most superior points of the anterior \\
(a) and posterior (p) borders of the \\
bodies of C2-4 \\
The middle of the upper border of the \\
bodies of C2-4 \\
The middle of the anterior border of the \\
bodies of C2-4
\end{tabular}

Ratios

\begin{tabular}{ll}
$\mathrm{AH} 2-4 / \mathrm{H} 2-4$ & Ratio of $\mathrm{AH} 2-4 / \mathrm{H} 2-4$ \\
$\mathrm{H} 2-4 / \mathrm{PH} 2-4$ & Ratio of $\mathrm{H} 2-4 / \mathrm{PH} 2-4$ \\
$\mathrm{AH} 2-4 / \mathrm{PH} 2-4$ & Ratio of $\mathrm{AH} 2-4 / \mathrm{PH} 2-4$ \\
$\mathrm{UW} 2-4 / \mathrm{W} 2-4$ & Ratio of $\mathrm{UW} 2-4 / \mathrm{W} 2-4$ \\
$\mathrm{~W} 2-4 / \mathrm{LW} 2-4$ & Ratio of $\mathrm{W} 2-4 / \mathrm{LW} 2-4$ \\
$\mathrm{UW} 2-4 / \mathrm{LW} 2-4$ & Ratio of $\mathrm{UW} 2-4 / \mathrm{LW} 2-4$ \\
$\mathrm{AH} 2-4 / \mathrm{UW} 2-4$ & Ratio of $\mathrm{AH} 2-4 / \mathrm{UW} 2-4$ \\
$\mathrm{H} 2-4 / \mathrm{UW} 2-4$ & Ratio of $\mathrm{H} 2-4 / \mathrm{UW} 2-4$ \\
$\mathrm{PH} 2-4 / \mathrm{UW} 2-4$ & Ratio of $\mathrm{PH} 2-4 / \mathrm{UW} 2-4$ \\
$\mathrm{AH} 2-4 / \mathrm{W} 2-4$ & Ratio of $\mathrm{AH} 2-4 / \mathrm{W} 2-4$ \\
$\mathrm{H} 2-4 / \mathrm{W} 2-4$ & Ratio of $\mathrm{H} 2-4 / \mathrm{W} 2-4$ \\
$\mathrm{PH} 2-4 / \mathrm{W} 2-4$ & Ratio of $\mathrm{PH} 2-4 / \mathrm{W} 2-4$ \\
$\mathrm{AH} 2-4 / \mathrm{LW} 2-4$ & Ratio of $\mathrm{AH} 2-4 / \mathrm{LW} 2-4$ \\
$\mathrm{H} 2-4 / \mathrm{LW} 2-4$ & Ratio of $\mathrm{H} 2-4 / \mathrm{LW} 2-4$ \\
$\mathrm{PH} 2-4 / \mathrm{LW} 2-4$ & Ratio of $\mathrm{PH} 2-4 / \mathrm{LW} 2-4$ \\
$\mathrm{OH} / \mathrm{UW} 2$ & Ratio of $\mathrm{OH} / \mathrm{UW} 2$ \\
$\mathrm{OH} / \mathrm{AH} 2$ & Ratio of $\mathrm{OH} / \mathrm{AH} 2$ \\
$\mathrm{OH} / \mathrm{H} 2$ & Ratio of $\mathrm{OH} / \mathrm{H} 2$ \\
$\mathrm{OH} / \mathrm{PH} 2$ & Ratio of $\mathrm{OH} / \mathrm{PH} 2$ \\
$\mathrm{OH} / \mathrm{UW} 2$ & Ratio of $\mathrm{OH} / \mathrm{UW} 2$ \\
$\mathrm{OH} / \mathrm{W} 2$ & Ratio of $\mathrm{OH} / \mathrm{W} 2$ \\
$\mathrm{OH} / \mathrm{LW} 2$ & Ratio of $\mathrm{OH} / \mathrm{LW} 2$ \\
$\mathrm{OH} / \mathrm{PH} 2$ & Ratio of $\mathrm{OH} / \mathrm{PH} 2$ \\
$(\mathrm{OH}+\mathrm{AH} 2) / \mathrm{UW} 2$ & Ratio of $(\mathrm{OH}+\mathrm{AH} 2) / \mathrm{UW} 2$ \\
$(\mathrm{OH}+\mathrm{AH} 2) / \mathrm{W} 2$ & Ratio of $(\mathrm{OH}+\mathrm{AH} 2) / \mathrm{W} 2$ \\
$(\mathrm{OH}+\mathrm{AH} 2) / \mathrm{LW} 2$ & Ratio of $(\mathrm{OH}+\mathrm{AH} 2) / \mathrm{LW} 2$ \\
$(\mathrm{OH}+\mathrm{H} 2) / \mathrm{UW} 2$ & Ratio of $(\mathrm{OH}+\mathrm{H} 2) / \mathrm{UW} 2$ \\
$(\mathrm{OH}+\mathrm{H} 2) / \mathrm{W} 2$ & Ratio of $(\mathrm{OH}+\mathrm{H} 2) / \mathrm{W} 2$ \\
$(\mathrm{OH}+\mathrm{H} 2) / \mathrm{LW} 2$ & Ratio of $(\mathrm{OH}+\mathrm{H} 2) / \mathrm{LW} 2$ \\
$(\mathrm{OH}+\mathrm{PH} 2) / \mathrm{UW} 2$ & Ratio of $(\mathrm{OH}+\mathrm{PH} 2) / \mathrm{UW} 2$ \\
$(\mathrm{OH}+\mathrm{PH} 2) / \mathrm{W} 2$ & Ratio of $(\mathrm{OH}+\mathrm{PH} 2) / \mathrm{W} 2$ \\
$(\mathrm{OH}+\mathrm{PH} 2) / \mathrm{LW} 2$ & Ratio of $(\mathrm{OH}+\mathrm{PH} 2) / \mathrm{LW} 2$ \\
\hline &
\end{tabular}

a very high coefficient 0.950 when the SML was substituted for the SMI. As a parametric method to present the degree of 
TABLE 3: Descriptive statistics for parameters in the C2, C3, and C4 vertebral bodies.

\begin{tabular}{lcccccccccccc}
\hline \multirow{2}{*}{ Parameter } & \multicolumn{4}{c}{ C2 vertebra } & \multicolumn{3}{c}{ C3 vertebra } & \multicolumn{3}{c}{ C4 vertebra } \\
& Mean & SD & Min & Max & Mean & SD & Min & Max & Mean & SD & Min & Max \\
\hline AH/H & 1.07 & 0.05 & 0.96 & 1.20 & 0.99 & 0.06 & 0.83 & 1.13 & 0.98 & 0.07 & 0.80 & 1.15 \\
HP/H & 1.15 & 0.05 & 1.01 & 1.29 & 0.99 & 0.05 & 0.90 & 1.17 & 0.97 & 0.05 & 0.86 & 1.07 \\
AH/PH & 1.23 & 0.09 & 0.97 & 1.41 & 0.99 & 0.07 & 0.79 & 1.15 & 0.95 & 0.07 & 0.74 & 1.08 \\
UW/W & 0.82 & 0.06 & 0.70 & 0.93 & 0.88 & 0.05 & 0.77 & 0.97 & 0.90 & 0.05 & 0.77 & 1.06 \\
W/LW & 1.10 & 0.08 & 0.83 & 1.26 & 1.08 & 0.04 & 0.98 & 1.17 & 1.06 & 0.05 & 0.96 & 1.18 \\
UW/LW & 0.90 & 0.08 & 0.74 & 1.10 & 0.95 & 0.07 & 0.83 & 1.12 & 0.95 & 0.07 & 0.77 & 1.18 \\
AH/UW & 1.27 & 0.11 & 0.99 & 1.55 & 1.05 & 0.20 & 0.55 & 1.41 & 1.00 & 0.20 & 0.51 & 1.37 \\
H/UW & 1.18 & 0.11 & 0.94 & 1.45 & 1.05 & 0.17 & 0.61 & 1.36 & 1.01 & 0.16 & 0.59 & 1.36 \\
PH/UW & 1.03 & 0.11 & 0.81 & 1.27 & 1.06 & 0.18 & 0.57 & 1.46 & 1.05 & 0.18 & 0.61 & 1.50 \\
AH/W & 1.04 & 0.08 & 0.86 & 1.26 & 0.91 & 0.15 & 0.51 & 1.20 & 0.89 & 0.15 & 0.48 & 1.17 \\
H/W & 0.97 & 0.08 & 0.78 & 1.15 & 0.92 & 0.12 & 0.56 & 1.15 & 0.90 & 0.12 & 0.56 \\
PH/W & 0.85 & 0.09 & 0.67 & 1.10 & 0.93 & 0.13 & 0.53 & 1.15 & 0.93 & 0.14 & 0.57 & 1.16 \\
AH/LW & 1.14 & 0.13 & 0.87 & 1.53 & 0.99 & 0.17 & 0.54 & 1.32 & 0.94 & 0.16 & 0.51 & 1.25 \\
H/LW & 1.06 & 0.11 & 0.85 & 1.37 & 0.99 & 0.14 & 0.57 & 1.27 & 0.96 & 0.13 & 0.59 & 1.24 \\
PH/LW & 0.93 & 0.11 & 0.74 & 1.21 & 1.00 & 0.15 & 0.54 & 1.27 & 0.99 & 0.15 & 0.59 & 1.33 \\
D & 1.75 & 0.62 & 0.06 & 3.11 & 1.73 & 0.64 & 0.01 & 3.11 & 1.51 & 0.60 & 0.12 & 2.75 \\
\hline
\end{tabular}

C2, second cervical; $\mathrm{C}$, third cervical; C4, fourth cervical; Min, minimum; Max, maximum; SD, standard deviation.

TABLE 4: Descriptive statistics for SML and parameters in the C2 vertebral body and odontoid process.

\begin{tabular}{lcccc}
\hline Parameters & Mean & SD & Min & Max \\
\hline SML & 82.02 & 16.20 & 18.30 & 96.50 \\
$\mathrm{OH} / \mathrm{UW} 2$ & 1.96 & 0.19 & 1.57 & 2.44 \\
$\mathrm{OH} / \mathrm{AH} 2$ & 1.55 & 0.15 & 1.14 & 2.04 \\
$\mathrm{OH} / \mathrm{H} 2$ & 1.67 & 0.16 & 1.28 & 2.10 \\
$\mathrm{OH} / \mathrm{PH} 2$ & 1.91 & 0.20 & 1.45 & 2.39 \\
$\mathrm{O} / \mathrm{UW} 2$ & 1.96 & 0.19 & 1.57 & 2.44 \\
$\mathrm{OH} / \mathrm{W} 2$ & 1.61 & 0.16 & 1.36 & 2.14 \\
$\mathrm{OH} / \mathrm{LW} 2$ & 1.76 & 0.15 & 1.36 & 2.14 \\
$(\mathrm{OH}+\mathrm{AH} 2) / \mathrm{UW} 2$ & 3.23 & 0.26 & 2.56 & 3.78 \\
$(\mathrm{OH}+\mathrm{AH} 2) / \mathrm{W} 2$ & 2.66 & 0.21 & 2.27 & 3.25 \\
$(\mathrm{OH}+\mathrm{AH} 2) / \mathrm{LW} 2$ & 2.90 & 0.24 & 2.23 & 3.50 \\
$(\mathrm{OH}+\mathrm{H} 2) / \mathrm{UW} 2$ & 3.15 & 0.26 & 2.56 & 3.74 \\
$(\mathrm{OH}+\mathrm{H} 2) / \mathrm{W} 2$ & 2.59 & 0.21 & 2.20 & 3.22 \\
$(\mathrm{OH}+\mathrm{H} 2) / \mathrm{LW} 2$ & 2.82 & 0.23 & 2.22 & 3.42 \\
$(\mathrm{OH}+\mathrm{PH} 2) / \mathrm{UW} 2$ & 3.00 & 0.26 & 2.47 & 3.59 \\
$(\mathrm{OH}+\mathrm{PH} 2) / \mathrm{W} 2$ & 2.46 & 0.22 & 2.10 & 3.20 \\
$(\mathrm{OH}+\mathrm{PH} 2) / \mathrm{LW} 2$ & 2.69 & 0.22 & 2.15 & 3.28 \\
\hline
\end{tabular}

$\mathrm{C} 2$, second cervical; Min, minimum; Max, maximum; SD, standard deviation.

correlation between two variables, we used the Shapiro-Wilk test $(P<0.05)$ to confirm the normality test in the sample distribution.

The descriptive statistics of each parameter (obtained from CBCT-generated CVM) are reported in Tables 3 and 4. We calculated the correlation coefficient from these data in order to find the correlation between the SML and the parameters from CBCT-generated CVM (Table 5). Out of a total of 64 parameters, 47 exhibited statistically significant correlations $(P<0.05)$. Regression analysis with the SML (a dependent variable) and 64 parameters from CBCTgenerated CVM (independent variables) were employed to build eight multiple regression models (Table 6). Among these models, the eighth multiple regression model (Table 6) featured the highest $R^{2}$ and adjusted $R^{2}$. The model with $\mathrm{PH} 2 / \mathrm{W} 2, \mathrm{UW} 2 / \mathrm{W} 2,(\mathrm{OH}+\mathrm{AH} 2) / \mathrm{LW} 2, \mathrm{UW} 3 / \mathrm{LW} 3, \mathrm{D} 3$, and $\mathrm{H} 4 / \mathrm{W} 4$, as independent variables, exhibited the highest coefficient of determination, 0.786 , indicating that approximately $78.6 \%$ of the variation in the SML could be explained by these independent variables. Aside from the significant enhancement of $R^{2}$, there was no significant multicollinearity between variables derived from regression models for the SML. We performed multicollinearity tests based on the variance inflation factor (VIF) $<2$, which indicated the absence of multicollinearity problems. The parameters $\mathrm{AH} 3 / \mathrm{W} 3$ and H4/W4 had high VIF values (>2.0) in the fourth, fifth, and sixth regression models. The models with these VIFs could have significant multicollinearity problems [21] (Table 6).

\section{Discussion}

Several methods for assessing skeletal maturation status have been introduced [1-4]. The CVM method has proven to be especially useful. Mito et al. [22] and Chen et al. [23] introduced multiple regression models in order to employ CVM to determine skeletal maturation stage. Mito et al. [22] created a regression formula to obtain cervical vertebral bone age; they reported that the formula was determined from the ratios of measurements in the third cervical vertebral (C3) and fourth cervical (C4) vertebral bodies. Chen et al. [23] also developed formulas that employed regression analysis to predict mandibular length increment using cervical vertebrae and used the ratios of $\mathrm{C} 3$ and $\mathrm{C} 4$ vertebral bodies and 


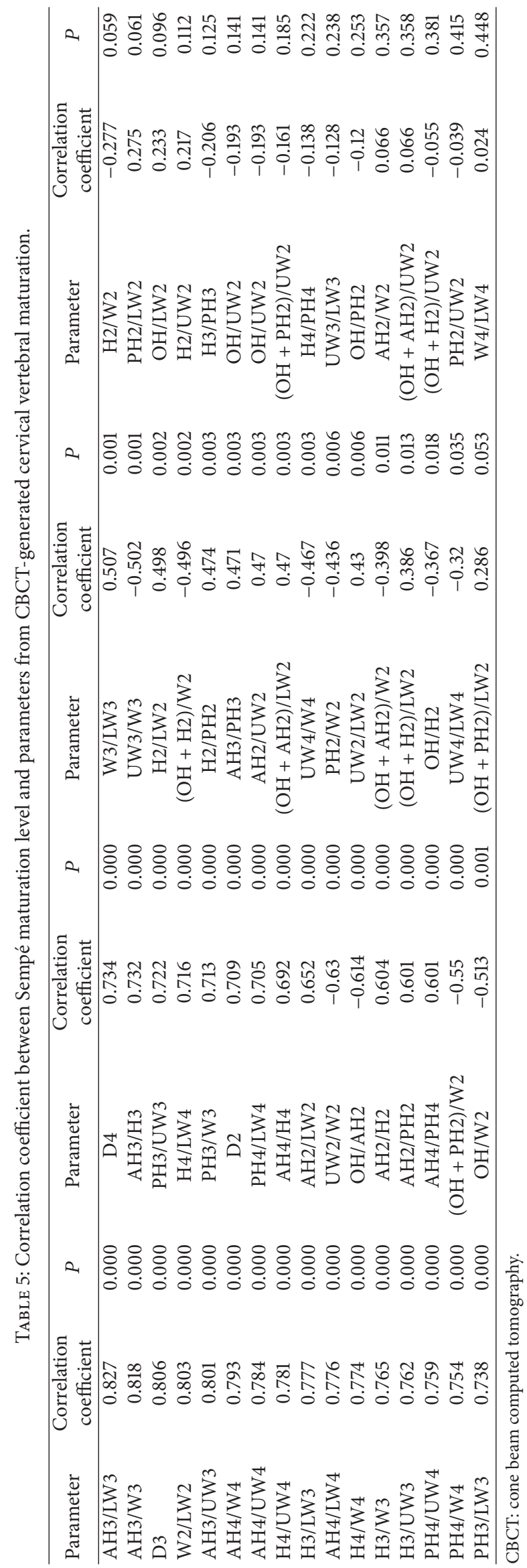


TABLE 6: The results of multiple regression analysis using the stepwise elimination method.

\begin{tabular}{|c|c|c|c|c|c|c|c|c|c|c|}
\hline $\begin{array}{l}\text { Multiple } \\
\text { regression } \\
\text { models }\end{array}$ & Independent variables & $B$ & SE & $ß$ & $t$ & $P$ & $R^{2}$ & Adjusted $R^{2}$ & VIF & $1 / \mathrm{VIF}$ \\
\hline \multirow{2}{*}{ 1st } & Intercept & 5.750 & 8.037 & & 0.715 & 0.477 & 0.562 & 0.556 & & \\
\hline & $\mathrm{AH} 3 / \mathrm{W} 3$ & 83.521 & 8.693 & 0.750 & 9.608 & 0.000 & & & 1.000 & 1.000 \\
\hline \multirow{3}{*}{ 2nd } & Intercept & 53.375 & 13.591 & & 3.927 & 0.000 & 0.647 & 0.637 & & \\
\hline & $\mathrm{AH} 3 / \mathrm{W} 3$ & 81.719 & 7.867 & 0.733 & 10.388 & 0.000 & & & 1.003 & 0.997 \\
\hline & $\mathrm{PH} 2 / \mathrm{W} 2$ & -54.228 & 13.080 & -0.293 & -4.146 & 0.000 & & & 1.003 & 0.997 \\
\hline \multirow{4}{*}{ 3rd } & Intercept & 102.021 & 19.993 & & 5.103 & 0.000 & 0.691 & 0.678 & & \\
\hline & $\mathrm{AH} 3 / \mathrm{W} 3$ & 76.606 & 7.584 & 0.687 & 10.102 & 0.000 & & & 1.051 & 0.951 \\
\hline & $\mathrm{PH} 2 / \mathrm{W} 2$ & -41.478 & 12.961 & -0.224 & -3.200 & 0.002 & & & 1.110 & 0.901 \\
\hline & UW2/W2 & -66.514 & 20.999 & -0.227 & -3.167 & 0.002 & & & 1.163 & 0.860 \\
\hline \multirow{5}{*}{4 th } & Intercept & 95.499 & 19.162 & & 4.984 & 0.000 & 0.725 & 0.709 & & \\
\hline & $\mathrm{AH} 3 / \mathrm{W} 3$ & 41.675 & 14.118 & 0.374 & 2.952 & 0.004 & & & 4.020 & 0.249 \\
\hline & $\mathrm{PH} 2 / \mathrm{W} 2$ & -48.406 & 12.567 & -0.261 & -3.852 & 0.000 & & & 1.152 & 0.868 \\
\hline & UW2/W2 & -66.554 & 19.985 & -0.227 & -3.330 & 0.001 & & & 1.163 & 0.860 \\
\hline & H4/W4 & 49.024 & 17.030 & 0.363 & 2.879 & 0.005 & & & 3.972 & 0.252 \\
\hline \multirow{6}{*}{5 th } & Intercept & 76.845 & 19.081 & & 4.027 & 0.000 & 0.758 & 0.740 & & \\
\hline & AH3/W3 & 28.671 & 13.984 & 0.257 & 2.050 & 0.044 & & & 4.426 & 0.226 \\
\hline & $\mathrm{PH} 2 / \mathrm{W} 2$ & -64.394 & 12.956 & -0.348 & -4.970 & 0.000 & & & 1.374 & 0.728 \\
\hline & UW2/W2 & -68.148 & 18.872 & -0.232 & -3.611 & 0.001 & & & 1.163 & 0.860 \\
\hline & H4/W4 & 51.692 & 16.099 & 0.382 & 3.211 & 0.002 & & & 3.984 & 0.251 \\
\hline & $(\mathrm{OH}+\mathrm{AH} 2) / \mathrm{LW} 2$ & 14.811 & 4.823 & 0.223 & 3.071 & 0.003 & & & 1.485 & 0.673 \\
\hline \multirow{7}{*}{ 6th } & Intercept & 65.500 & 19.341 & & 3.387 & 0.001 & 0.774 & 0.753 & & \\
\hline & $\mathrm{AH} 3 / \mathrm{W} 3$ & 15.279 & 15.001 & 0.137 & 1.018 & 0.312 & & & 5.361 & 0.187 \\
\hline & $\mathrm{PH} 2 / \mathrm{W} 2$ & -61.331 & 12.709 & -0.331 & -4.826 & 0.000 & & & 1.392 & 0.718 \\
\hline & UW2/W2 & -57.274 & 19.086 & -0.195 & -3.001 & 0.004 & & & 1.252 & 0.799 \\
\hline & H4/W4 & 53.176 & 15.708 & 0.393 & 3.385 & 0.001 & & & 3.992 & 0.251 \\
\hline & $(\mathrm{OH}+\mathrm{AH} 2) / \mathrm{LW} 2$ & 15.836 & 4.726 & 0.239 & 3.351 & 0.001 & & & 1.501 & 0.666 \\
\hline & D3 & 4.444 & 2.079 & 0.176 & 2.138 & 0.036 & & & 1.999 & 0.500 \\
\hline \multirow{6}{*}{ 7th } & Intercept & 64.128 & 19.300 & & 3.323 & 0.001 & 0.770 & 0.753 & & \\
\hline & $\mathrm{PH} 2 / \mathrm{W} 2$ & -63.747 & 12.490 & -0.344 & -5.104 & 0.000 & & & 1.344 & 0.744 \\
\hline & UW2/2 & -57.027 & 19.090 & -0.194 & -2.987 & 0.004 & & & 1.252 & 0.799 \\
\hline & H4/W4 & 65.587 & 9.915 & 0.485 & 6.615 & 0.000 & & & 1.590 & 0.629 \\
\hline & $(\mathrm{OH}+\mathrm{AH} 2) / \mathrm{LW} 2$ & 17.357 & 4.485 & 0.262 & 3.870 & 0.000 & & & 1.351 & 0.740 \\
\hline & D3 & 5.328 & 1.889 & 0.211 & 2.820 & 0.006 & & & 1.651 & 0.606 \\
\hline \multirow{7}{*}{ 8th } & Intercept & 96.052 & 23.595 & & 4.071 & 0.000 & 0.786 & 0.767 & & \\
\hline & $\mathrm{PH} 2 / \mathrm{W} 2$ & -62.449 & 12.154 & -0.337 & -5.138 & 0.000 & & & 1.347 & 0.742 \\
\hline & $\mathrm{UW} 2 / \mathrm{W} 2$ & -54.843 & 18.581 & -0.187 & -2.952 & 0.004 & & & 1.256 & 0.796 \\
\hline & $\mathrm{H} 4 / \mathrm{W} 4$ & 63.270 & 9.693 & 0.468 & 6.527 & 0.000 & & & 1.608 & 0.622 \\
\hline & $(\mathrm{OH}+\mathrm{AH} 2) / \mathrm{LW} 2$ & 16.076 & 4.397 & 0.242 & 3.656 & 0.001 & & & 1.374 & 0.728 \\
\hline & D3 & 5.593 & 1.840 & 0.221 & 3.039 & 0.003 & & & 1.658 & 0.603 \\
\hline & UW3/LW3 & -31.028 & 13.910 & -0.129 & -2.231 & 0.029 & & & 1.047 & 0.955 \\
\hline
\end{tabular}

$B$, unstandardized regression coefficient; $\mathrm{SE}$, standard error of $B ; \beta$, standardized regression coefficient; VIF, variance inflation factor. 
the lower concavity angle of $\mathrm{C} 2$ as independent variables. However, in this study, we defined the measurements of the C2 vertebral body and the odontoid process. The dentocentral synchondrosis was considered the border between the body and the odontoid process of $\mathrm{C} 2$. The results showed that the ratios of the $\mathrm{C} 2$ body and the odontoid process were correlated very highly with skeletal maturation status (as did the bodies of the third and fourth cervical vertebrae, which were used in the previous studies) (Tables 5 and 6).

During embryonic development, the second cervical vertebra arises from five primary bone growth centers (one occurs in the body, two occur in bilateral neural arches, and the other two occur in the odontoid process) separated by synchondrotic articulations [24, 25]. The two in the odontoid process are fused at birth. The border between the odontoid process and the body of the axis vertebra is well demarcated by the dentocentral synchondrosis [26]. The bilateral neurocentral synchondroses between the bilateral neural arch and the dentocentral synchondrosis fuse at 3 to 6 years of age. After 6 years of age, the odontoid process fuses with the vertebral body and the neural arches [26]. The remnant of the dentocentral synchondrosis, which is below the superior articulating facets, appears on CBCT and MRI images as a ring. Çokluk et al. [16] compared the odontoid process-to-vertebral body ratios between children and adults, based on MRIs of the dentocentral synchondrosis. Therefore, we were able to use CBCT images to define the vertebral body and its odontoid process and expected that the odontoid process and vertebral body might be important independent variables for the regression model derived from CBCT-generated CVM.

Several studies used the third and fourth vertebral bodies and the concavity of their lower borders to assess skeletal maturation $[10,22,23]$. They reported that many ratios of the width and height of the C3 and C4 were correlated with skeletal maturation status. In the present study, 47 of 64 parameters exhibited statistically significant correlations $(P<0.05)$, similar to the findings of other previous studies (Table 5). The C2 vertebral body and odontoid process were significant independent variables in all multiple regression models. In the multiple regression model with the highest $R^{2}$, adjusted $R^{2}$, and variance inflation factors (VIF) $<2$, which indicated the absence of multicollinearity problems, $\mathrm{PH} 2 / \mathrm{W} 2, \mathrm{UW} 2 / \mathrm{W} 2,(\mathrm{OH}+\mathrm{AH} 2) / \mathrm{LW} 2, \mathrm{UW} 3 / \mathrm{LW} 3, \mathrm{D} 3$, and H4/W4 were independent variables. This model also exhibited the highest coefficient of determination, 0.786 , indicating that these independent variables were able to explain approximately $78.6 \%$ of the SML variation.

While the ratios of the third and fourth cervical vertebrae had strong correlation coefficients in previous CVM studies, the present study added the ratio of the second cervical vertebra, which correlated strongly with CBCT-generated CVM as an indicator. Altan et al. [27] investigated the longitudinal growth of cervical vertebrae in girls from 8 to 17 years of age. The growth of the cervical vertebrae follows a somatic pattern, and they reach their final size at maturity [28]. C1 and C4 reached their peak size at approximately 11.5 years of age, and C3 reached its maximal size at 10.5 years of age. However, the growth curve for C2 did not have a distinct peak growth rate; its growth rate curve was more linear [29]. Therefore, in this study, the parameters of the $\mathrm{C} 2$ vertebral body and the odontoid process might be independent variables for the multiple linear regression model because it has a more linear growth pattern. Our findings indicated that the growth of $\mathrm{C} 2$ vertebral body and odontoid process might be a useful indicator for evaluating the stages of skeletal maturation. The multiple regression models put forth by Chen et al. [23] and Mito et al. [22] included parameters such as the height/width ratios of the third and fourth cervical vertebrae as independent variables. However, regression models in our study with $\mathrm{AH} 3 / \mathrm{H} 3$ and $\mathrm{H} 4 / \mathrm{W} 4$ ratios had multicollinearity problems with high VIF values (Table 6).

Similarly, the third and fourth cervical vertebrae arise from three primary ossification centers (one in the body and two in the posterior arches) $[30,31]$. The shape of the bodies of third and fourth cervical vertebrae changes from wedge-shaped to rectangular and then becomes square. Their shapes grow vertically and then horizontally. The total length and height of the third and fourth cervical vertebrae have very similar incremental curves. Cervical vertebral growth occurred in the order of the upper to the lower cervical vertebrae. Therefore, these parameters might induce statistical multicollinearity problems. Many clinical studies regarding dental research have used multiple regression analysis to find correlations between the predictor and the outcome variables. However, collinearity in the statistic regression models is one possible problem with the use of multiple regression analysis. "Multicollinearity" is the statistical term for the situation in which more than two covariates are highly correlated [21]. It can distort the interpretation of statistical results from multiple regression models, increasing both inaccuracy and uncertainty. Multicollinearity should be considered in the regression model.

We used the SML as a measure of the study participants' skeletal maturation status in order to build the multiple regression models in this study. The SML comprises 1000 stages, numbered from 0 to 999 ; compared to 11 stages, it provides a more refined skeletal maturation status as a percentage. The SML (with stages 0 to 999) was pertinent to statistical analysis as a parametric dependent variable for multiple regression models. The present study has already confirmed its high correlation to Fishman's SMI for building multiple regression models $(P<0.05$; correlation coefficient, 0.950).

Other CVM-based studies had large study populations that were heterogeneous regarding sex and ethnicity. Although our study population was comparatively small and homogeneous, this study had the advantage of introducing the modified CBCT-generated CVM with the defined body of the second cervical vertebra and the odontoid process from the dentocentral synchondrosis. Given this CBCT approach, the study could not have a large study population. Despite these difficulties, this study demonstrated a new application of the second cervical vertebral body and odontoid to the CBCT-generated CVM and resulted in the building of multiple regression models. We expect that sexual 
dimorphism may imply divergence between boys and girls during the course of ossification. Ethnicity may explain the relatively high correspondence of ossification level observed in the present study compared with other studies. Therefore, additional studies are needed to address questions regarding sexual dimorphism and ethnicity.

\section{Conclusions}

CBCT-generated CVM was able to include parameters from the second cervical vertebral body and the odontoid process, respectively, for multiple regression models. The derived multiple regression models demonstrated the potential of the newly defined parameters of the second cervical vertebra.

\section{Conflict of Interests}

All of the authors declare that there is no conflict of interests regarding the publication of this paper.

\section{Acknowledgment}

This study was supported by two-year research grant from Pusan National University (Woo-Sung Son).

\section{References}

[1] U. Hägg and J. Taranger, "Maturation indicators and the pubertal growth spurt," American Journal of Orthodontics, vol. 82, no. 4, pp. 299-309, 1982.

[2] T. Uysal, Z. Sari, S. I. Ramoglu, and F. A. Basciftci, "Relationships between dental and skeletal maturity in Turkish subjects," Angle Orthodontist, vol. 74, no. 5, pp. 657-664, 2004.

[3] M. T. O'Reilly and G. J. Yanniello, "Mandibular growth changes and maturation of cervical vertebrae-a longitudinal cephalometric study," Angle Orthodontist, vol. 58, no. 2, pp. 179-184, 1988.

[4] W. W. Greulich and S. I. Pyle, Radiographic Atlas of Skeletal Development of the Hand and Wrist, Stanford University Press, Stanford, Calif, USA, 1959.

[5] A. B. Lewis and S. M. Garn, "The relationship between tooth formation and other maturation factors," The Angle Orthodontist, vol. 30, no. 2, pp. 70-77, 1960.

[6] C. J. Hunter, "The correlation of facial growth with body height and skeletal maturation at adolescence," The Angle Orthodontist, vol. 36, no. 1, pp. 44-54, 1966.

[7] A. Björk and S. Helm, "Prediction of the age of maximum puberal growth in body height," Angle Orthodontist, vol. 37, no. 2, pp. 134-143, 1967.

[8] M. I. Tofani, "Mandibular growth at puberty," The American Journal of Orthodontics, vol. 62, no. 2, pp. 176-195, 1972.

[9] U. Hagg and J. Taranger, "Menarche and voice change as indicators of the pubertal growth spurt," Acta Odontologica Scandinavica, vol. 38, no. 3, pp. 179-186, 1980.

[10] P. San Román, J. C. Palma, M. D. Oteo, and E. Nevado, "Skeletal maturation determined by cervical vertebrae development," European Journal of Orthodontics, vol. 24, no. 3, pp. 303-311, 2002.

[11] L. Franchi, T. Baccetti, and J. A. McNamara Jr., "Mandibular growth as related to cervical vertebral maturation and body height," American Journal of Orthodontics and Dentofacial Orthopedics, vol. 118, no. 3, pp. 335-340, 2000.

[12] T. Baccetti, L. Franchi, and J. A. McNamara Jr., "An improved version of the cervical vertebral maturation (CVM) method for the assessment of mandibular growth," The Angle Orthodontist, vol. 72, no. 4, pp. 316-323, 2002.

[13] D. B. Gabriel, K. A. Southard, F. Qian, S. D. Marshall, R. G. Franciscus, and T. E. Southard, "Cervical vertebrae maturation method: poor reproducibility," The American Journal of Orthodontics and Dentofacial Orthopedics, vol. 136, no. 4, pp. 478.e1-478.e7, 2009.

[14] L.-L. Chen, T.-M. Xu, J.-H. Jiang, X.-Z. Zhang, and J.-X. Lin, "Quantitative cervical vertebral maturation assessment in adolescents with normal occlusion: a mixed longitudinal study," American Journal of Orthodontics and Dentofacial Orthopedics, vol. 134, no. 6, pp. 720.el-720.e7, 2008.

[15] A. Chatzigianni and D. J. Halazonetis, "Geometric morphometric evaluation of cervical vertebrae shape and its relationship to skeletal maturation," American Journal of Orthodontics and Dentofacial Orthopedics, vol. 136, no. 4, pp. 481.e1-481.e9, 2009.

[16] C. Çokluk, K. Aydm, C. Rakunt, O. Iyigun, and A. Onder, “The borders of the odontoid process of $\mathrm{c} 2$ in adults and in children including the estimation of odontoid/body ratio," European Spine Journal, vol. 15, no. 3, pp. 278-282, 2006.

[17] V. Joshi, T. Yamaguchi, Y. Matsuda, N. Kaneko, K. Maki, and T. Okano, "Skeletal maturity assessment with the use of conebeam computerized tomography," Oral Surgery, Oral Medicine, Oral Pathology and Oral Radiology, vol. 113, no. 6, pp. 841-849, 2012.

[18] J. B. Ludlow, L. E. Davies-Ludlow, S. L. Brooks, and W. B. Howerton, "Dosimetry of $3 \mathrm{CBCT}$ devices for oral and maxillofacial radiology: CB Mercuray, NewTom $3 \mathrm{G}$ and i-CAT," Dentomaxillofacial Radiology, vol. 35, no. 4, pp. 219-226, 2006.

[19] M. Sempé, La Pédiatrie au Quotidian. Analyse de la Maturation Sequelettique Les Editions, INSERM, Paris, France, 1987.

[20] L. S. Fishman, "Radiographic evaluation of skeletal maturation. A clinically oriented method based on hand-wirst films," Angle Orthodontist, vol. 52, no. 2, pp. 88-112, 1982.

[21] J. Miles and M. Shelvin, Applying Regression and Correlation, Sage Publication, London, UK, 2001.

[22] T. Mito, K. Sato, and H. Mitani, "Cervical vertebral bone age in girls," The American Journal of Orthodontics and Dentofacial Orthopedics, vol. 122, no. 4, pp. 380-385, 2002.

[23] F. Chen, K. Terada, and K. Hanada, "A new method of predicting mandibular length increment on the basis of cervical vertebrae," Angle Orthodontist, vol. 74, no. 5, pp. 630-634, 2004.

[24] H. Herkowitz, S. Garfin, F. Eismont, G. Bell, and R. Balderston, Rothman-Simeone: The Spine, WB Saunders, Philadelphia, Pa, USA, 2011.

[25] A. Verbout, "The development of the vertebral column," Advances in Anatomy, Embryology and Cell Biology, vol. 90, no. 1, pp. 1-122, 1985.

[26] K. B. Arbogast, P. A. Gholve, J. E. Friedman, M. R. Maltese, M. F. Tomasello, and J. P. Dormans, "Normal cervical spine range of motion in children 3-12 years old," Spine, vol. 32, no. 10, pp. E309-E315, 2007.

[27] M. Altan, Ö. Nebioğlu Dalc, and H. Işeri, "Growth of the cervical vertebrae in girls from 8 to 17 years. A longitudinal study, European Journal of Orthodontics, vol. 34, no. 3, pp. 327334, 2012. 
[28] R. S. Tulsi, "Growth of the human vertebral column. An osteological study," Acta Anatomica, vol. 79, no. 4, pp. 570-580, 1971.

[29] N. Yoganandan, F. A. Pintar, S. M. Lew, R. D. Rao, and N. Rangarajan, "Quantitative analyses of pediatric cervical spine ossification patterns using computed tomography," Annals of Advances in Automotive Medicine, vol. 55, no. 1, pp. 159-168, 2011.

[30] S. Chandraraj and C. A. Briggs, "Multiple growth cartilages in the neural arch," The Anatomical Record, vol. 230, no. 1, pp. 114$120,1991$.

[31] D. M. Ford, K. D. McFadden, and K. M. Bagnall, "Sequence of ossification in human vertebral neural arch centers," Anatomical Record, vol. 203, no. 1, pp. 175-178, 1982. 


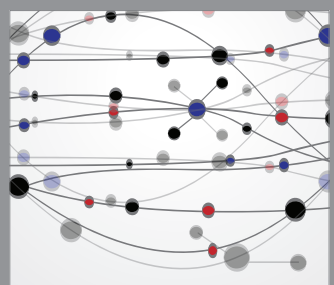

The Scientific World Journal
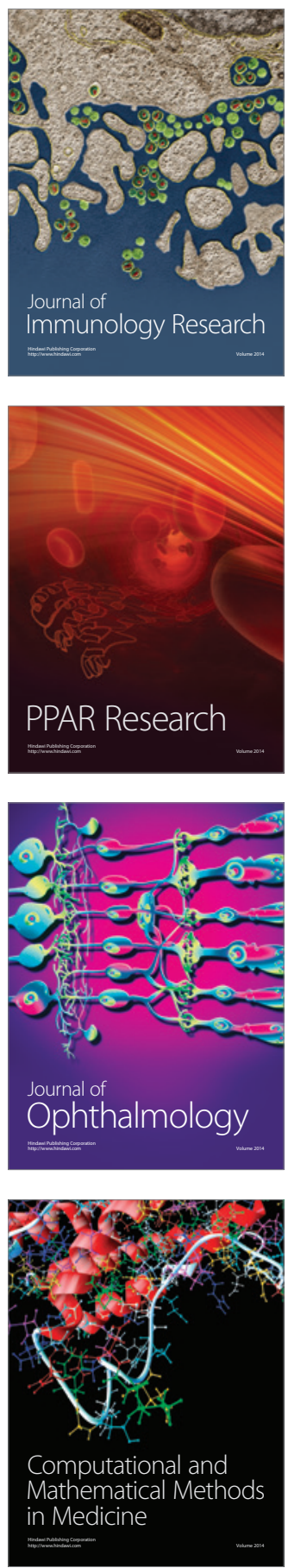

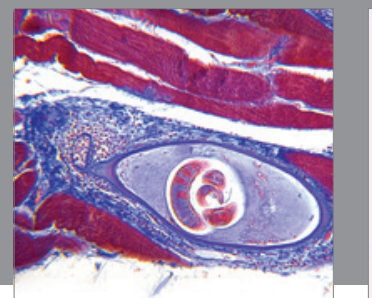

Gastroenterology

Research and Practice
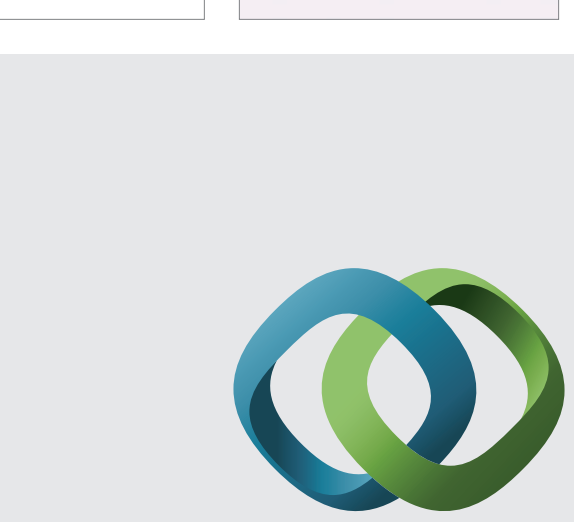

\section{Hindawi}

Submit your manuscripts at

http://www.hindawi.com
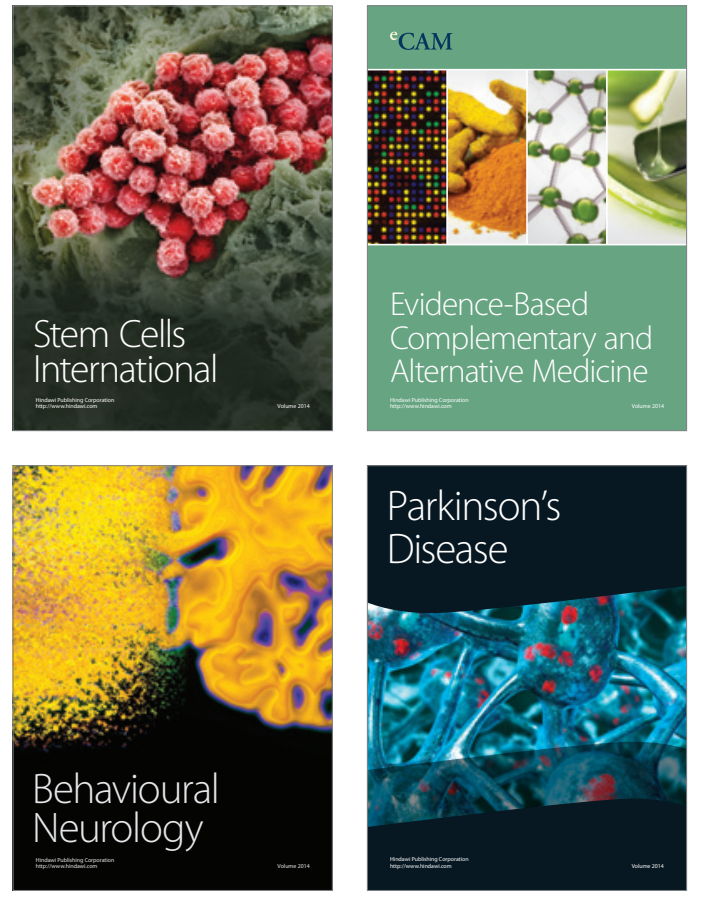
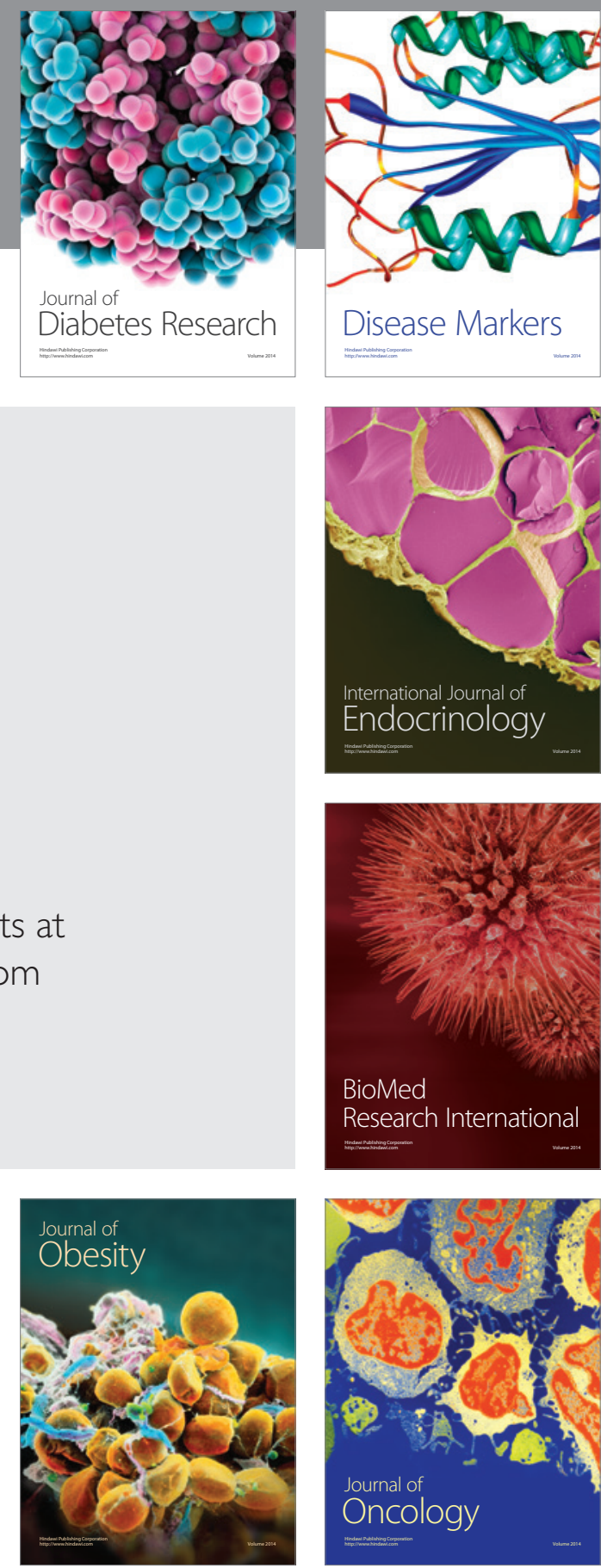

Disease Markers
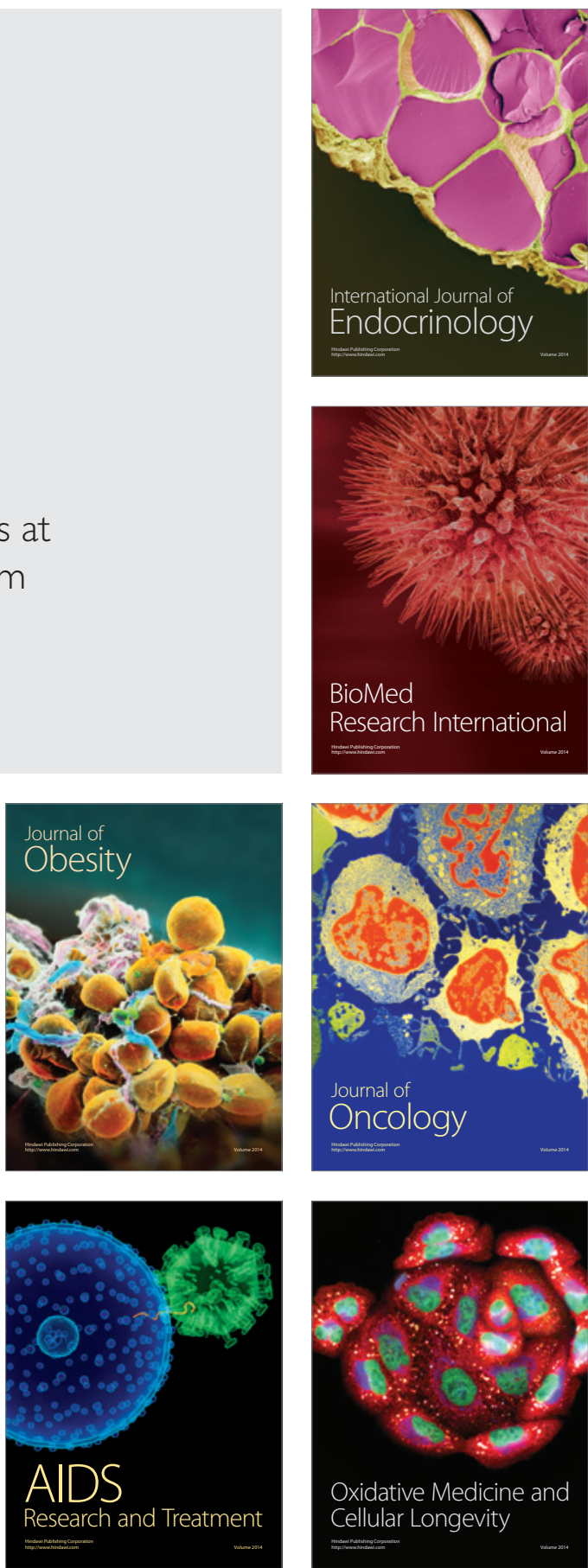